\title{
Modeling drying kinetics of fever leaves (Ocimum viride) in a convective hot air dryer
}

\author{
Sobukola, O.P. ${ }^{1}{ }^{*}$ and Dairo, O.U. ${ }^{2}$ \\ ${ }^{1}$ Department of Food Science and Technology, University of Agriculture, \\ P.M.B. 2240, Abeokuta, Nigeria \\ ${ }^{2}$ Department of Agricultural Engineering, University of Agriculture, \\ P.M.B. 2240, Abeokuta, Nigeria \\ *Address for Correspondence:Email: Author: olajidephilip@yahoo.com
}

ABSTRACT

\begin{abstract}
The drying behavior of fever leaves was investigated in a convective hot air dryer with forced convection at a fixed air velocity of $1.5 \mathrm{~m} / \mathrm{s}$ and drying air temperatures of 35 , 45,55 and $65^{\circ} \mathrm{C}$. The constant rate period was absent and the drying curve took place in the falling rate period. Experimental data was fitted to six thin-layer drying models - Page, Modified page II, Henderson and Pabis, Modified Henderson and Pabis, Two term and Newton. The performances of the models were investigated by comparing the coefficient of determination (R2), reduced chi-square $(\div 2)$ and root mean square error (RMSE)
\end{abstract}

between observed and predicted moisture ratios. The page model showed a good agreement with the data obtained while the effect of drying air temperature on the constants and coefficient of the page model was investigated. The effective diffusivity increases as temperature increases and range between $5.551 \times 10-12-3.379 \times 10-11 \mathrm{~m}^{2} / \mathrm{s}$ while the activation energy was estimated to be $80.78 \mathrm{~kJ} / \mathrm{mol}$.

Keywords: Fever leaves, convective hot air drying, modeling, diffusivity, activation energy

\section{INTRODUCTION}

$\mathrm{F}$ ever leaves (Ocimum viride) are very common leafy vegetable in Nigeria and West Africa where it is widely used in preparation of various soups. It is being used as a medicinal and aromatic plant since ancient times. These leaves are also commonly used for flavouring, local concoction infusions and spicing. Leafy vegetables play a very important role in our diet and nutrition since they are a major source of not only raw fiber but also essential nutrients, vitamins and minerals. The seasonal mature of there production together with their high water content which makes them highly perishable, has led to the search for different technologies (refrigeration, drying processes etc) to preserve them and allow availability at anytime. One of the simplest methods to improve the shelf life of leafy vegetables like fever leaves is to reduce their moisture content to such extent that the micro-organism cannot grow (Sobukola et al., 2006).

Drying of agricultural products has always been of great importance for the preservation of food by human beings (Togrul and Pehlivan, 2004). Open-air sun drying has been used since time immemorial to dry grains, vegetables, fruits and other agricultural products. However, openair natural sun drying is not always suited to large scale production due to some factors. Among them, the most important ones include: lack of ability to control the drying operation properly, the length of drying time, weather uncertainties, high labour costs, large area requirements, insect infestation, mixing with dust and other foreign materials and so on. The resulting loss of food 
quality in the dried products may have adverse economic effects on domestic and international markets (Lahsasni et al., 2004). Hence, the drying process may be conducted using several convective hot air dryer.

Quantitative understanding of drying operations is of great practical and economic importance. An understanding of the fundamental mechanisms, and knowledge of the moisture and temperature distributions within the product, is crucial for process design, quality control, product handling and energy savings (McMinn, 2006). A number of complex theoretical models to describe the heat and mass transfer phenomena during drying are available. However, both design and process engineers involved in industrial drying operations clearly need simple, but accurate, analytical tools, in order to conduct design analysis and relevant calculations (McMinn, 2006). Availability of such correlations and models, verified by experimental data will enable engineers and operators to provide optimum solutions to aspects of drying operations such as energy use, operating conditions and process control, without undertaking experimental trails on the system (Dincer, 1998). In particular, thin layer equations contribute to the understanding of the heat and mass transfer equations phenomena, and computer simulations, for designing new processes and improving existing commercial operations (Kardum et al., 2001).

Thin layer equations which describe the drying phenomena in a unified way regardless of the controlling mechanism have been used to estimate drying times of several products and to generalize drying curves. In the development of thin layer models for agricultural products, generally the moisture content of the material at anytime after it has been subjected to a constant relative humidity and temperature condition is measured and correlated to the drying parameter
(Midilli et al., 2002). Several thin layer equations available in literature have been successfully used to explain drying of several agricultural products. These include grains (Cao et al., 2004); fruits (Doymaz, 2004a); vegetables (Doymaz, 2004b); leaves and grasses (Sobukola et al., 2006; Demir et al., 2004); Kale leaves (Mwithiga and Olwal, 2005). However, the authors have not found any literature on the convective hot air drying of fever leaves in thin layer. Therefore, the present study was undertaken with the following objectives

(i) to determine the effect of air temperature on the drying behaviour of fever leaves in a convective hot air dryer

(ii) to calculate the effective diffusivity and activation energy of samples; and

(iii) to fit the experimental drying data obtained to drying models widely used to describe thin-layer drying of agricultural products.

\section{MATERIALS AND METHODS}

Fresh fever leaves (Ocimum viride) used in this study was procured from a local market in Abeokuta, Nigeria and used immediately for the drying experiments. The drying experiments were conducted at forced convection mode at 35 , 45,55 and $65^{\circ} \mathrm{C}$ and $1.5 \mathrm{~m} / \mathrm{s}$ drying velocity using a hot air convective dryer (Gallenkamp SG 94/ 04/609, U.K.). The drying system was run for about 40 minutes to obtain a stable condition before placing samples in the chamber. The initial weights of the fever leaves were about $25 \pm 5 \mathrm{~g}$ and the drying operation started with an initial moisture content of about $83 \%$ (w.b) and continued until no further changes in their mass were observed i.e. to the final moisture content of about $<10 \%$ (w.b) which was taken as the equilibrium moisture content. This method has earlier been used by McMinn (2006). Drying tests were conducted in triplicates at each air temperature and means are reported. Moisture 
contents of fresh and dried samples were determined using the oven dry method at $105^{\circ} \mathrm{C}$ for $5 \mathrm{~h}$ (AOAC, 1990).

\section{Analysis of drying data}

The experimental drying data obtained were fitted to the six well-known thin layer drying models given in Table 1 . The moisture ratio was obtained from equation (1):

$M R=\frac{X-X_{e}}{X_{o}-X_{e}}$

where MR is the dimensionless moisture ratio, $\mathrm{X}, \mathrm{Xe}$ and $\mathrm{Xo}$ are the moisture ratios at any time, the equilibrium moisture content and the initial moisture content in $\%$ wb respectively (Sacilik et al., 2006).

The drying rate of the leaves was calculated using equation (2) (Akpinar et al., 2003).

$$
\text { Dryingrate }=\frac{M_{t+d t}-M_{t}}{d t}
$$

where $\mathrm{Mt}+\mathrm{dt}$ and $\mathrm{Mt}$ are moisture content at $\mathrm{t}+\mathrm{dt}$ ( $\mathrm{kg}$ water/kg dry matter) and moisture content at time $t$ respectively and $t$ is drying time (min).

Regression analysis was performed using data fit 6.1 version (Oakdale Engineering, 1999, USA). The coefficient of determination (R2) was the primary criterion for selecting the best model to describe the drying curves (Guarte, 1996). In addition to $\mathrm{R} 2$, the deviations between experimental and predicted values for the models and root mean square error analysis (RMSE) were used to determine the goodness of the fit. The higher the values of R2 and the lowest values of $\div 2$ and RMSE, the better the goodness of the fit (Midilli and Kucuk, 2003). They were calculated as:

$$
R^{2}=\frac{\sum_{i=1}^{n}\left(M R_{i}-M R_{\text {pre }, i}\right) \sum_{i=1}^{n}\left(M R_{i}-M R_{\mathrm{exp}, i}\right)}{\sqrt{\left(\sum_{i=1}^{n}\left(M R_{i}-M R_{p r e, i}\right)^{2}\right) \cdot\left(\sum_{i=1}^{n}\left(M R_{i}-M R_{\mathrm{exp}, i}\right)^{2}\right)}}
$$

$$
\chi^{2}=\frac{\sum_{i=1}^{n}\left(M R_{\exp , i}-M R_{p r e, i}\right)^{2}}{N-Z}
$$

$$
R M S E=\left[\frac{1}{n} \sum_{i=1}^{n}\left(M R_{\text {pre }, i}-M R_{\exp , i}\right)^{2}\right]^{1 / 2}
$$

where MRexp, $\mathrm{i}$ is the ith experimentally observed moisture ratio, MRpre, $\mathrm{i}$ is the ith predicted moisture ratio, $\mathrm{N}$ the number of observations and $\mathrm{Z}$ is the number of constants (Gunhan et al., 2005).

The effect of some parameters related to the product or drying conditions such as thickness, drying air temperature, relative humidity etc were investigated by many researchers (Akpinar et al., 2006; Ertekin and Yaldiz, 2004; Togrul and Pehlivan, 2004; Yaldiz and Ertekin, 2001). Modeling the drying behaviour of different agricultural products often requires the statistical methods of regression models and correlation analysis. Linear and non-linear regression models are important tools to find relationship between different variables, especially for which no established empirical relationship exists. In this study, at drying process in a convective hot air dryer with forced convection mode, the relationships of the constants of the best suitable model with the drying air temperature was also determined by multiple regression technique using Arrhenius, exponential and power regression models (Akpinar et al., 2003) which are most common mathematical expressions.

\section{RESULTS AND DISCUSSION Drying curves}

Figures 1 and 2 show the variation of moisture ratios of fever leaves with the drying time and the drying rates versus drying time respectively. It is apparent that the drying rate decreased continuously with the moisture or 
drying time. From Fig. 1, it is clearly evident that the drying time decreases with increase in drying air temperature. Hence, experimental results showed that the drying air temperature has a significant effect on the evolution of moisture content. No constant rate drying period was observed in these curves and all drying operations are seen to occur in the falling rate period. These results are in agreement with the earlier observations (Togrul and Pehlivan, 2004; Gunhan et al., 2005; Mwithiga and Olwal, 2005; Akpinar et al., 2005; Sobukola et al., 2006). The increase in drying rate as temperature of drying air increases as shown in Fig. 2 is due to increased heat transfer gradient between the air and the leaves which favours water evaporation from the leaves (Doymaz, 2006). In general, the time required to reduce the moisture ratio to any given level was dependent on the drying conditions, being the highest at $35^{\circ} \mathrm{C}$ and the lowest at $65^{\circ} \mathrm{C}$. Similar observations have been reported by Simal et al. (1996) and Ertekin and Yaldiz (2004).

\section{Estimation of effective diffusivity and activation energy}

Interpretation of the experimental data was done using the Fick's diffusion model. General series solution of Fick's second laws in slabs with the assumptions of moisture migration being by diffusion, negligible shrinkage, constant diffusion coefficients and temperature is given as (Crank, 1975);

$$
M R=\frac{X-X_{e}}{X_{O}-X_{e}}=\frac{6}{\pi^{2}} \sum_{n=2}^{\infty} \frac{1}{n^{2}} \exp \left(\frac{-n^{2} \pi^{2} D_{\text {eff }} . t}{L^{2}}\right)
$$

For long drying periods, Eq. (6) can be further simplified to only the first term of the series and the moisture ratio (MR) reduced to $\mathrm{X} /$ Xo because Xe was relatively small compared to $\mathrm{X}$ and Xo. Hence, Eq. (6) can be written in logarithmic form:

$$
\ln =\frac{X}{X_{O}}=\ln \left(\frac{6}{\pi^{2}}\right)-\frac{\pi^{2} D_{\text {eff }} \cdot t}{L^{2}}
$$

where $\mathrm{L}$ is the equivalent half thickness of the leaf being dried in $\mathrm{m}, \mathrm{n}$ is a positive integer and Deff is the effective diffusivity in $\mathrm{m}^{2} / \mathrm{s}$. From Eq. (7), a plot of $\ln (\mathrm{MR})$ versus drying time gave a straight line with the slope of $\ln (\mathrm{MR})$ versus drying time gave a straight line with the slope of:

$$
\text { Slope }=\frac{\pi^{2} D_{\text {eff }}}{L^{2}}
$$

The values of Deff for the samples are as shown in Table 2. The effective diffusivity of the samples was influenced by the air drying temperature. These values increased with increase in the air temperature due to rapid movement of water at high temperatures. For this study, Deff values varied between 5.51 x 10-12 $-3.379 \times 10-11 \mathrm{~m}^{2} / \mathrm{s}$. These values were observed to be within the general range of $0.8 \times 10-13-$ $64.6 \times 10-10 \mathrm{~m}^{2} / \mathrm{s}$ for drying of food materials (Doulia et al., 2000; Sacilik et al., 2006).

The effect of air temperature on the effective diffusivity is expressed using the Arrhenius-type relationship:

$$
D_{\text {eff }}=D_{o} \exp \left(\frac{-E_{a}}{R T_{a}}\right)
$$

where Do is the pre-exponential factor of the Arrhenius equation in $\mathrm{m}^{2} / \mathrm{s}$, Ea is the activation energy in $\mathrm{kJ} / \mathrm{mol}, \mathrm{R}$ is the universal gas constant in $\mathrm{kJ} / \mathrm{mol} \mathrm{K}$ and $\mathrm{Ta}$ is the absolute air temperature in $\mathrm{K}$.

A plot of natural logarithm of Deff against reciprocal of the absolute temperatures gave a straight line graph in the range of air temperature studied. The activation energy for diffusion was evaluated from the slope of straight line and was found to be $80.78 \mathrm{~kJ} / \mathrm{mol}$. Similar results have been reported by Park et al. (2002); Panchariya et al. (2002) and Doymaz (2006).

\section{Fitting of the drying curves}

In order to determine the moisture content as a funcmodified Page II, Henderson and Pabis, 
modified Henderson and Pabis, Two-term and Newton models were fitted. Table 3, presents the results of non-linear regression analysis of the six models. The entire model gave consistently high coefficient of determination (R2) values in the range of $0.99242-0.99999$. This is an indication that all the models could satisfactorily describe the air drying of fever leaves.

Among the thin-layer drying models, the page and modified page II models obtained the highest $\mathrm{R} 2$ values and the lowest $\div 2$ and RMSE values in the range of $35-550 \mathrm{C}$ drying air temperature. However, at $650 \mathrm{C}$ drying air temperature, the page, modified page II, modified Henderson and Pabis and Newton models can be used to predict drying characteristics of fever leaves since they all have the highest R2 of 0.99997. On close examination of the table, the reduced chi-square $(\div 2)$ of the page and modified page II have the lowest values hence could adequately predicts the drying kinetics of fever leaves.

In order to study the effect of temperature on drying rate, and hence the best among page and modified page II, the rate constants of the two models were correlated against temperature. The average values of constants a and n over the experimental temperature was used (Mwithiga and Olwal, 2005). So, equations (10) and (11) representing the drying characteristics of fever leaves under convective drying within the temperature range of $35-65 \mathrm{oC}$ for the two models were developed. Eq. (10) and (11) were tested to obtain the moisture ratio of fever leaves using the drying time data and values obtained were compared with experimental values.

Page model: $\mathrm{n}=2.44044$,

$$
K=\exp \left(0.8302-\frac{125.2312}{T_{a}}\right)
$$

$(\mathrm{R} 2=0.96504, \mathrm{SEE}=0.0269)$

Modified page II: $n=2.44044$,

$$
\begin{aligned}
& K=\exp \left(-0.5588-\frac{42.3695}{T_{a}}\right) \\
& (\mathrm{R} 2=0.9206, \mathrm{SEE}=0.0193)
\end{aligned}
$$

Since, the coefficients of the page model is marginally superior, as well as having the highest R2 value, the model best represents the drying behaviour of fever leaves. Figure 3 shows experimental and predicted (page model) moisture ratios values against drying time. From the figure, it clearly shows that the page model is able to predict the moisture ratio accurately over the period of drying.

\section{CONCLUSION}

In this study, the drying behaviour of fever leaves (Ocimum viride) was investigated in a convective hot air dryer with forced convection mode. The drying process at each temperature of study occurred in the falling rate period, no constant rate period of drying was observed. The drying behaviour was explained using six thin layer drying models and the results showed that the page model was observed to be most suitable for describing the drying curve of fever leaves with R2 of $0.99996-0.99999 ; \div 2$ of 0.00000028 - 0.00000598; and RMSE of 0.000475 0.0020667 for between $35-650 \mathrm{C}$ air drying temperature and $1.5 \mathrm{~m} / \mathrm{s}$ air velocity. The constants and coefficients of page model were explained by the effect of drying air temperature with a coefficient of determination (R2) of 0.96504 . The effective diffusivity range between $5.551 \times 10-12-3.379 \times 10-11 \mathrm{~m} 2 / \mathrm{s}$ and increases as temperature increases while the activation energy was obtained to be $80.78 \mathrm{~kJ} / \mathrm{mol}$. 


\section{REFERENCES}

Akpinar, E.K., Bicer, Y. and Cetinkaya, F. (2006). Modeling of thin layer drying of parsley leaves in a convective dryer and under open sun. Journal of Food Engineering, 75, 308-315.

Akpinar, E.K., Bicer, Y. and Midilli, A. (2003). Modeling and experimental study on drying of apple slices in a convective cyclone dryer. Journal of Food Process Engineering, 26(2): 515 -541 .

AOAC (1990). Official method of analysis. No. 934.06 Association of Official Analytical Chemists, Arlington, USA.

Cao, W., Nishiyama, Y., Koide, S., and Lu, H.Z. (2004). Drying enhancement of rough rice by electric field. Biosystems Engineering. 84(4): $445-451$.

Crank, J. (1975). Mathematics of diffusions (2nd ed.) London: Oxford University Press.

Demir, V., Gunhan, T., Yagcioglu, A.K. and Degirmencioglu, A. (2004). Mathematical modeling and determination of some quality parameters of air-dried bay leaves. Biosystems Engineering, 88(3):325-335.

Dincer, I. (1998). Moisture loss from wood products during drying - part II: surface moisture content distributions. Energy source, 20(1), 7783.

Doulia, D., Tizia, K., and Gekas, G. (2000). A knowledge base for apparent mass diffusivity coefficient (Deff) of foods: physical properties of food database. Nelfood.com, Available from http://www.nelfood.com.

Doymaz, I (2006). Thin layer drying behaviour of mint leaves. Journal of Food Engineering, 74, 370-375.
Doymaz, I (2004a). Drying kinetic of white mulberry. Journal of Food Engineering, 74, 341346.

Doymaz, I (2004b). Pretreatment effect on sun drying of mulberry fruit (Morusalba L.). Journal of Food Engineering, 65(2): 205-209.

Ertekin, C., and Yaldiz, O. (2004). Drying of eggplant and selection of suitable thin layer drying model. Journal of Food Engineering, 63(3):349-359.

Guarte, R.C. (1996). Modeling the drying behaviour of copra and development of a Natural convection dryer for production of high quality cogra in the Philippines. PhD Dissertation. Stuttgart, Germany: Hohenhaim University.

Gunhan, T., Demir, V., Hancioglu, E., and Hepbasli, A. (2005). Mathematical modeling of drying bay leaves. Energy conversion and management, 46(11-12): 1667 - 1679.

Kardum, J.P., Sander, A. and Skansi, D. (2001). Comparison of convective, vacuum and microwave drying of Chlorpropamide. Drying Technology, 19(1), 167-183.

Lahsasni, S., Kouhila, M., Mahrouz, M., Idliman, A. and Jamali, A. (2004). Thin layer convective solar drying and mathematical modeling of prickly pear pae (Opuntia ficus indica). Energy, 29(2): $211-224$.

McMinn, W.A.M. (2006). Thin layer modeling of the convective, microwave, microwave. Convective and microwave-vacuum drying of lactose powder. Journal of Food Engineering, 72, 113-123. 
Midilli, A., Kucuk, H., and Yapar, Z. (2002). A new model for single layer drying. Drying Technology, 20(7): 1503-1513.

Midilli, A. and Kucuk, H. (2003). Mathematical modeling of thin layer drying of Pistachia by using solar energy. Energy conversion and Management, 44 (7): 1111-1122.

Mwithiga, G. and Olwal, J.O. (2005). The drying kinetics of kale (Brassica oleracea) in a convective hot air dryer. Journal of Food Engineering, 71, 373-378.

Panchariya, P.C., Popovic, D. and Sharma, A.L. (2002). Thin-layer modeling of black tea drying process. Journal of Food Engineering, 52(4): 349-357.

Park, K.J., Vohnikova, Z. and Brod, F.P.R. (2002). Evaluation of drying parameters and desorption isotherms of garden mint leaves (Mentha crispa. L). Journal of Food Engineering, 51, 193-199.
Sacilik, K., Elicin, A.K. and Unal, G. (2006). Drying kinetics of Uryani plum in a convective hot air dryer. Journal of Food Engineering, 76, 362-388.

Simal, S., Mulet, A., Tarrazo, J. and Rosella, C. (1996). Drying models for green peas. Food Chemistry, 55, 121-128.

Sobukola, O.P., Dairo, O.U., Sanni, L.O., Odunewu, A.V. and Fafiolu B.O. (2006). Mathematical modeling of thin layer drying of fever leaves (Ocimum viride) under open sun. A paper presented at the 2nd National drying symposium (NDS) at Nigerian stored Produce Research Institute (NSPRI), Ilorin, Kwara State.

Togrul, I.T. and Pehlivan, D. (2004). Modeling of thin layer drying kinetics of some fruits under open-air sun drying process. Journal of Food Engineering, 65, 413-425.

Yaldiz, O. and Ertekin, C. (2001). Thin layer solar drying of some different vegetables. Drying Technology, 19(2): $583-596$.

Table 1. Mathematical models applied to the drying curves (Akpinar et al., 2006; Doymaz, 2006, Sacilik et al., 2006).

\begin{tabular}{llc}
\hline Model no & Model name & Model $(\mathbf{M R}=)$ \\
\hline 1 & Page & $\exp \left(-\mathrm{kt}^{\mathrm{n}}\right)$ \\
2 & Modified page II & $\exp \left[(-\mathrm{kt})^{\mathrm{n}}\right]$ \\
3 & Henderson and Pabis & aexp $(-\mathrm{kt})$ \\
4 & Modified Henderson and Pabis & aexp $(-\mathrm{kt})+\mathrm{bexp}(-\mathrm{gt})+\mathrm{cexp}(-\mathrm{ht})$ \\
5 & Two term & aexp $\left(-\mathrm{k}_{\mathrm{o}} \mathrm{t}\right)+\mathrm{bexp}\left(-\mathrm{k}_{1} \mathrm{t}\right)$ \\
6 & Newton & $\exp (-\mathrm{kt})$ \\
\hline
\end{tabular}


Table 2. Effective diffusivity values for fever leaves at different drying air temperature.

\begin{tabular}{cc}
\hline Drying air temperature $\left({ }^{\circ} \mathrm{C}\right)$ & Effective diffusivity $\left(\mathrm{m}^{2} / \mathrm{s}\right)$ \\
\hline 35 & $5.551 \times 10-12$ \\
45 & $1.139 \times 10-11$ \\
55 & $2.589 \times 10-11$ \\
65 & $3.379 \times 10-11$ \\
\hline
\end{tabular}

Table 3. Statistical results obtained from various thin-layer drying model

\begin{tabular}{|c|c|c|c|c|}
\hline Model no & Temperature $\left({ }^{\circ} \mathrm{C}\right)$ & $\mathbf{R}^{2}$ & RMSE & $\mathbf{x}^{2}$ \\
\hline 1 & 35 & 0.99996 & 0.0020667 & \\
\hline \multicolumn{5}{|l|}{0.00000598} \\
\hline & 45 & 0.99999 & 0.0004475 & \\
\hline \multicolumn{5}{|l|}{0.00000028} \\
\hline & 55 & 0.99996 & 0.0020559 & \\
\hline 0.00000592 & 65 & 0.99997 & 0.0017959 & \\
\hline \multicolumn{5}{|l|}{0.00000258} \\
\hline & 35 & 0.99996 & 0.0020667 & \\
\hline \multicolumn{5}{|l|}{0.00000598} \\
\hline 2 & 45 & 0.99999 & 0.0004475 & \\
\hline \multicolumn{5}{|l|}{0.00000028} \\
\hline & 55 & 0.99996 & 0.0020559 & \\
\hline \multicolumn{5}{|l|}{0.00000592} \\
\hline & 65 & 0.99997 & 0.0017959 & \\
\hline 0.00000258 & 35 & 00.99254 & 0.0023999 & \\
\hline \multicolumn{5}{|l|}{0.00000806} \\
\hline & 45 & 0.99647 & 0.0205448 & \\
\hline 0.00059092 & 3 & 55 & 0.99991 & 0.0032420 \\
\hline \multicolumn{5}{|l|}{0.00001472} \\
\hline & 65 & 0.99992 & 0.0022804 & $0.00001257 \mathrm{~s}$ \\
\hline & 35 & 0.99254 & 0.0023999 & \\
\hline \multicolumn{5}{|l|}{0.00000032} \\
\hline & 45 & 0.99647 & 0.0205448 & \\
\hline 0.00295461 & & & & \\
\hline
\end{tabular}




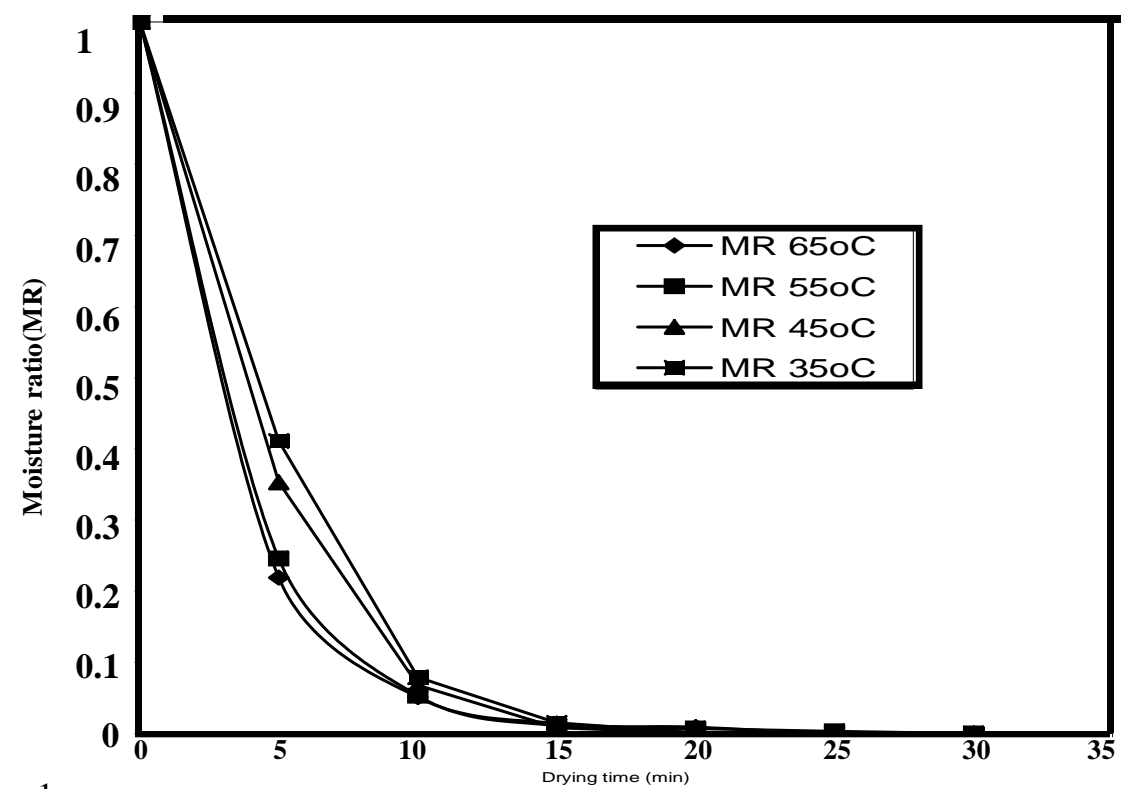

Fig. 1. Variations of moisture ratio as a function of time for different air drying temperature

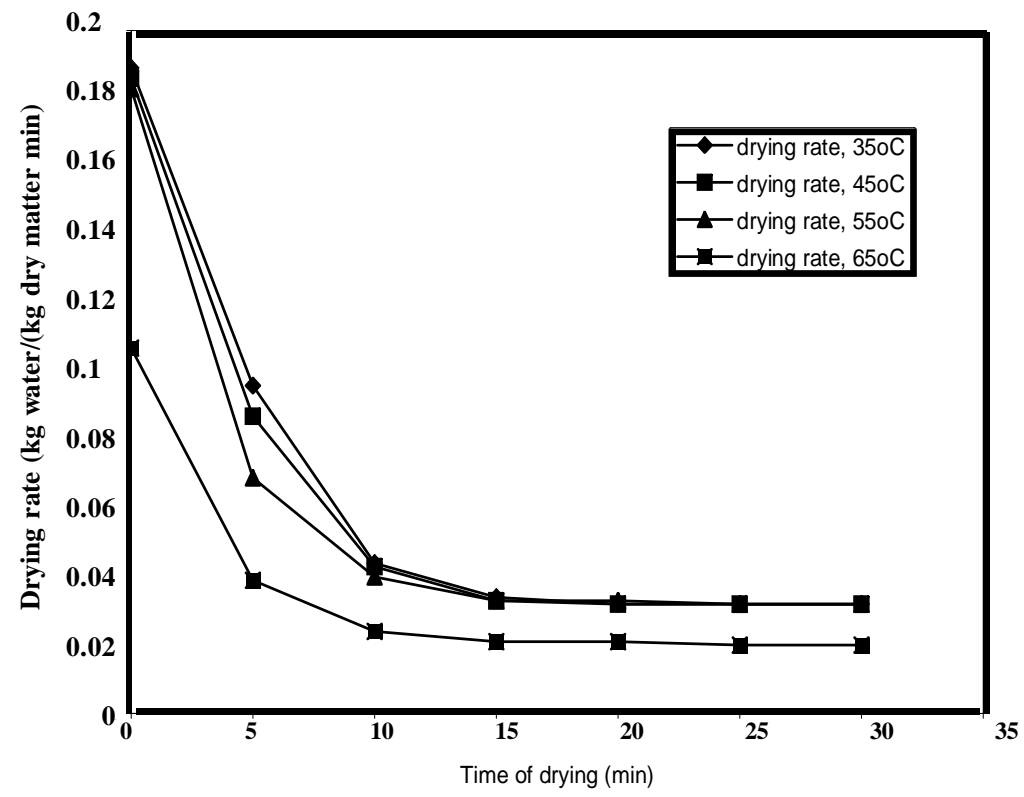

Fig. 2 Variation of drying rate as a function of drying time for different air drying temperatures 